\section{NCCN Guidelines: Pretransplant Recipient Evaluation and Management of Graft-Versus-Host Disease}

\author{
Corey Cutler, MD, MPH, FRCP(C), and Steven Z. Pavletic, MD, MS
}

T This edition of JNCCN includes the first iteration of the NCCN Clinical Practice Guidelines in Oncology (NCCN Guidelines) for Hematopoietic Cell Transplantation (HCT), with a focus on pretransplant evaluation and management of graft-versus-host disease (GVHD).

Substantial progress has been made in acute and chronic GVHD clinical classification and trial design, and the discovery of new therapeutic targets has propelled the field rapidly forward. ${ }^{1-3}$ However, the basic principles of GVHD clinical management have not changed, though they have become more complicated with the development and even FDA approval of new drugs for this indication. Similarly, use of HCT has shifted with the development of novel therapeutics in leukemia and lymphoma and the emergence of a new field of immunotherapy. With the near universal availability of donors for each patient who requires transplantation, often difficult decisions need to be made regarding the appropriateness of HCT over these novel therapies. Clinicians must now consider the fact that patients live longer, and live better, after transplantation for a variety of reasons.

With this in mind, the number of transplant recipients alive and at risk for longterm complications of cancer therapy and HCT is increasing rapidly. Although excellent guidelines on the recommended long-term management of HCT survivors exist, ${ }^{4}$ there has been a long-recognized need for guidelines for GVHD management. Other societies have thus far shied away from publishing authoritative guidelines in the absence of rigorous evidence, although one comprehensive review and recommendation on the topic has been published. ${ }^{5}$

These first NCCN Guidelines are a well-intended attempt to start addressing the need for guidance in HCT for general oncology practitioners, but add little for the subspecialist transplant physician. They provide a framework for the development of comprehensive guidelines in the future and endorse all essential contemporary diagnostic standards. However, this first version is incomplete in several areas, leaving substantial room for improvement in future editions. For example, the refined Mount Sinai Acute GVHD International Consortium (MAGIC) classification of acute GVHD should be endorsed as a current standard, widely accepted by lead organizations in HCT for its improved practicality. 6,7 This system has at least equaled if not supplanted the modified Glucksberg criteria in common use. ${ }^{8}$ The guidelines also do not mention the burgeoning field of biomarkers in GVHD and whether these should be used in any of the algorithms or in acute GVHD clinical trials. ${ }^{9}$ There is no reference to the crucial role of organ-directed therapy and supportive care in the treatment of chronic GVHD, a topic that already has an authoritative treatment guide. ${ }^{10}$ An overly uninformative approach is taken to corticosteroid tapering schedules, an aspect of paramount importance in successful GVHD management. No mention is made regarding the importance of referral to a tertiary transplant center. General statements that monitoring for posttransplant complications is required make no reference to the potential differences in complications facing patients undergoing autologous and allogeneic HCT. Omissions such as

See page 599 for related article.

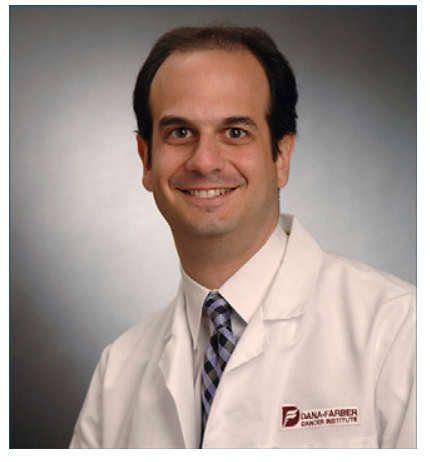

COREY CUTLER, MD, MPH, $\operatorname{FRCP}(\mathbf{C})$

Corey Cutler, MD, MPH, $\operatorname{FRCP}(C)$, is an Associate Professor of Medicine at Harvard Medical School, and an Institute Physician in the Division of Hematologic Oncology, Department of Medical Oncology at DanaFarber Cancer Institute and Brigham and Women's Hospital, Boston. He is the Medical Director of the Stem Cell Transplantation Program at Dana-Farber and an affiliate faculty member of the Harvard Stem Cell Institute, Cambridge.

Dr. Cutler graduated from McGill University's Faculty of Medicine, completed a residency in Internal Medicine at McGill University Health Science Center, and completed fellowship training in hematology, medical oncology, and stem cell transplantation at the Dana-Farber Cancer Institute. Dr. Cutler earned an MPH degree at the Harvard School of Public Health.

Currently, Dr. Cutler is on the Board of Directors of the American Society of Blood and Marrow Transplantation and is Chair of the CIBMTR Nominating Committee. He is on the editorial board of the journal Biology of Blood and Marrow Transplantation. $\mathrm{He}$ has been a contributing author on more than 300 peer-reviewed publications and 25 reviews and book chapters. His research focuses on development of novel methods of acute and chronic graft-versus-host disease prophylaxis and therapy, umbilical cord blood transplantation, and decision theory in stem cell transplantation.

doi: $10.6004 /$ jnccn.2020.7575

The ideas and viewpoints expressed in this commentary are those of the authors and do not necessarily represent any policy, position, or program of NCCN. 


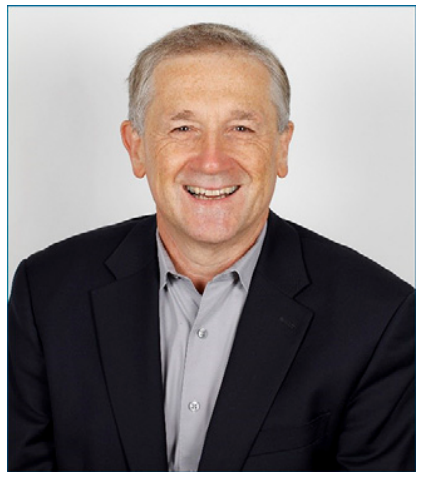

STEVEN Z. PAVLETIC, MD, MS

Steven Z. Pavletic, MD, MS, is Head of the Graft-versus-Host and Late effects Section in the Immune Deficiency Cellular Therapy Program, Center for Cancer Research, NCl, $\mathrm{NIH}$. He also directs the NIH intramural chronic GVHD study group and codirects the new NIH Intramural Program in myeloid malignancies/MDS.

Dr. Pavletic received his MD from the University of Zagreb School of Medicine in Croatia and completed a clinical fellowship in bone marrow transplantation at the Fred Hutchinson Cancer Research Center and University of Washington Medical School, Seattle. He completed an internal medicine residency and hematology oncology fellowship at the University of Nebraska Medical Center and served as director of the Allogeneic Stem Cell Transplantation Program there until moving to the $\mathrm{NCl}$ in 2002. He has contributed to more than 300 peer-reviewed journal articles and book chapters. In 2006, he received the NIH Director's award for achievements in developing national and international consensus guidelines for clinical trials in chronic GVHD. He cochairs the 2020 NIH 3rd chronic GVHD consensus project. He is currently a member of the CIBMTR Advisory Committee and cochair of the American Society of Hematology Task Force for Immunotherapies. these leave the novice reader with little to no guidance on crucial topics relevant to the care of patients who have undergone HCT.

However, despite numerous shortcomings of this first attempt at developing NCCN Guidelines for HCT, we offer the following as the strengths of this document:

- The continued recommendation of clinical trials. Although several large, phase III randomized trials have been completed in recent years, by no means are HCT and GVHD evidence-based fields. We have now developed the tools necessary to help formalize what was previously a clinician's gestalt, now recognized by the regulatory agency. Now we should put these tools to the test with more innovative clinical trial designs and studies that effectively compare emerging and established therapeutics. Only through the rigorous testing of drugs and interventions will we be able to build algorithmic approaches to the challenges of HCT medicine.

- Naming off-label drugs as acceptable choices in the therapy of acute and chronic GVHD. To date, only 2 drugs are specifically indicated in GVHD, despite the fact that $>20$ compounds have been tested and are used with some degree of regularity by practicing clinicians. Although listing potential agents alphabetically in the guidelines is egalitarian, the 2 drugs with FDA approval in acute and chronic GVHD (albeit based on uncontrolled, openlabel studies) should be highlighted in the algorithmic approach to the choice of second-line agents and beyond for their respective conditions. Having a listing of agents with some claim to efficacy in GVHD provides practitioners some leverage with payers for what is clearly an orphan disease, where a degree of art is required to accompany the practice of medicine.

- Providing the necessary impetus to drive a true communal, sustained, and tedious, detail-oriented effort to develop expert recommendations for HCT and GVHD management guidelines. No one set of guidelines can be considered the gold standard unless the entire community of stakeholders is included in the process, and in this case, the contributions, support, and leadership of organizations such as the American Society for Transplantation and Cellular Therapy, European Society for Blood and Marrow Transplantation, NIH Consensus Development Projects on Criteria for Clinical Trials in Chronic GVHD, cGVHD Eurograft group, Chronic GVHD Consortium, and MAGIC, among others, as well as patient-led organizations, is required.

Disclosures: Dr. Cutler is a member of the Board of Directors of the American Society for Transplantation and Cellular Therapy. Dr. Pavletic is on the Steering Committee of the NIH Chronic GVHD Consensus Project. All opinions expressed in this article are the authors' own and do not necessarily reflect positions of their institutions, organizations, or the U.S. government.

Correspondence: Steven Z. Pavletic, MD, MS, Center for Cancer Research, National Cancer Institute, 10 Center Drive, Room 10/CRC 4-3130, Bethesda, MD 20892. Email: pavletis@mail.nih.gov

\section{References}

1. Zeiser R, Blazar BR. Acute graft-versus-host disease: biologic process, prevention, and therapy. N Engl J Med 2017;377:2167-2179.

2. Lee SJ, Wolff D, Kitko C, et al. Measuring therapeutic response in chronic graft-versus-host disease. National Institutes of Health consensus development project on criteria for clinical trials in chronic graftversus-host disease: IV. The 2014 Response Criteria Working Group Report. Biol Blood Marrow Transplant 2015;21:984-999.

3. Cutler CS, Koreth J, Ritz J. Mechanistic approaches for the prevention and treatment of chronic GVHD. Blood 2017;129:22-29.

4. Majhail NS, Rizzo JD, Lee SJ, et al. Recommended screening and preventive practices for long-term survivors after hematopoietic cell transplantation. Biol Blood Marrow Transplant 2012;18:348-371. 
5. Martin PJ, Rizzo JD, Wingard JR, et al. First- and second-line systemic treatment of acute graft-versus-host disease: recommendations of the American Society of Blood and Marrow Transplantation. Biol Blood Marrow Transplant 2012;18:1150-1163.

6. Harris AC, Young R, Devine $S$, et al. International, multicenter standardization of acute graft-versus-host disease clinical data collection: a report from the Mount Sinai Acute GVHD International Consortium. Biol Blood Marrow Transplant 2016;22:4-10.

7. Schoemans HM, Lee SJ, Ferrara JL, et al. EBMT-NIH-CIBMTR Task Force position statement on standardized terminology \& guidance for graftversus-host disease assessment. Bone Marrow Transplant 2018;53:1401-1415.
8. Przepiorka D, Weisdorf D, Martin P, et al. 1994 Consensus Conference on Acute GVHD Grading. Bone Marrow Transplant 1995;15: 825-828.

9. Levine JE, Braun TM, Harris AC, et al. A prognostic score for acute graftversus-host disease based on biomarkers: a multicentre study. Lancet Haematol 2015;2:e21-29.

10. Carpenter PA, Kitko CL, Elad S, et al. National Institutes of Health Consensus Development Project on Criteria for Clinical Trials in Chronic Graft-versus-Host Disease: V. The 2014 Ancillary Therapy and Supportive Care Working Group Report. Biol Blood Marrow Transplant 2015;21:1167-1187.

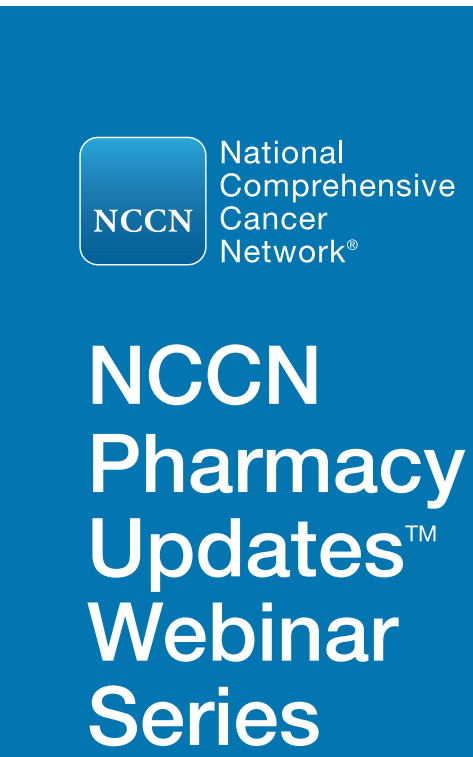

Updates on the Use of Immunotherapy and Targeted Therapy in Non-Small Cell Lung Cancer Thursday, May 21, 2020 • 1:00 - 2:00 PM EDT Jennifer Piccolo, PharmD, BCOP William S. Middleton Memorial Veterans Hospital

\section{The Role of the Pharmacist in Smoking} Cessation and Education of Patients with Cancer Monday, June 8, 2020 • 1:00 - 2:00 PM EDT

Kelly Gaffney, PharmD, BCOP

Case Comprehensive Cancer Centerl

University Hospitals Seidman Cancer Center and

Cleveland Clinic Taussig Cancer Institute

\section{education.nccn.org/pharmacy-updates}

NCCN designates each of these application-based activities for 1.0 contact hour ( 0.10 CEUs) of continuing education. Complete accreditation information is available online.

This activity is supported by an educational grant from AstraZeneca; Celgene Corporation; Coherus Biosciences; Novartis; and Servier Pharmaceuticals, LLC. This activity is supported by an independent educational grant from AbbVie. This activity is supported by an independent medical education grant from educational grant from AbbVie. This activity is supported by an independent medical education gran
Advancer Accelerator Applications, a Novartis Company; and Mylan Inc. This educational activity is supported by a medical education grant from Exelixis, Inc. 